\title{
Sport and active recreation injuries in Australia: evidence from emergency department presentations
}

\author{
Caroline Finch, Giulietta Valuri, Joan Ozanne-Smith
}

\begin{abstract}
Objective-Despite the rise in specialist clinical services for the management of sports and active recreation injury, many patients attend hospital emergency departments for treatment. The purpose of this study was to describe sports injury cases presented to selected hospital emergency departments around Australia for the period 1989-1993.
\end{abstract}

Methods-Routinely collected emergency department injury presentation data from the Australian National Injury Surveillance Unit were examined. Data on 98040 sports and active recreation emergency department presentations were analysed. Sports and active recreation activities were ranked according to frequency of presentation. Relative proportions of injury type and body region injured were determined. Data are presented separately for children ( $<15$ years of age) and adults ( $>15$ years of age).

Results-Among the 10 activities that most commonly led to a sports or active recreation injury presentation for all ages were cycling, Australian football, basketball, soccer, cricket, netball, and rugby. For children, injuries were also commonly associated with roller skating/blading, skateboarding, and trampolining. Hockey, martial arts, and dancing injuries were frequent in adults. Most sporting injuries occurred during organised competition or practice whereas the active recreation injuries occurred in a variety of settings. Fractures, strains, and sprains, particularly to the lower and upper extremities, were common types of injury.

Conclusion-The rich, but nevertheless limited, information available about sports and active recreation injuries from data collected in emergency departments indicates that these activities are a common context for injury at the community level in Australia.

(Br J Sports Med 1998;32:220-225)

Keywords: active recreation injury; surveillance data; emergency department presentations; community level.

Apart from a limited number of studies in progress, little systematic epidemiological research has been undertaken on sports and active recreational injuries at the broad community level in Australia. ${ }^{1}$ The only wide reaching collections of sports injury data in
Australia are through hospital based systems of admissions and emergency department presentations. ${ }^{1}$ There have, however, been reports of sports injuries in particular groups of sports participants, particularly the elite..$^{2-8}$

Egger ${ }^{9}$ produced one of the first Australian reports focusing on the causes, cost, and prevention of sports injuries. That report identified eight sports that were estimated to account for $75 \%$ of all sports injuries in Australia. These eight sports were four codes of football (Australian rules, rugby league, rugby union, soccer), basketball, netball, hockey, and cricket (indoor and outdoor).

Injury surveillance systems based on different health services-for example, hospital emergency departments and specialist clinics - are only able to describe part of the sports injury problem. Nevertheless, hospital based sports injury data collections are particularly useful for describing data on severe and/or acute sports injuries. Sports injuries are the third most common reason for a hospital admission due to injury in young people in the Australian State of Victoria. ${ }^{10}$ Similarly, data from emergency department presentations in Victoria have indicated that sports and active recreation injuries in children are the single highest cause of attendance at emergency departments as the result of injury. ${ }^{11}$ Only a proportion of all individuals with sports injuries will present at, or be admitted to, a hospital for treatment, and so data from this source will underestimate the true magnitude of sports injuries as a community public health problem. ${ }^{12}$

In a large postal survey in the United Kingdom of exercise related morbidity among adults aged 16-45 years, Nicholl et al ${ }^{13}$ found that treatment was sought in about $25 \%$ of all new exercise related morbidity incidents. Of these new cases, $28 \%$ were treated in hospital emergency departments.

Pickard et $a l^{12}$ noted a significant limitation of injury data based on attendances at a hospital emergency department for describing sports injuries. Although such data systems may be reasonable for general community level sport, professional and elite level sports often employ adequate first aid and medical back up services. This results in reduced referrals to a hospital for treatment of professional athletes, and again emergency department data provide an underestimate of the true magnitude of the problem.

Notwithstanding the above limitations, a number of studies have found emergency 
Table 1 The 10 most frequent sport and active recreation activities leading to emergency department injury presentation in children in Australia, 1989-93

\begin{tabular}{lllll}
\hline $\begin{array}{l}\text { Rank } \\
\text { order }\end{array}$ & Sport & $\begin{array}{l}\text { No of } \\
\text { presentations }\end{array}$ & $\begin{array}{l}\text { Proportion of } \\
\text { all sports injury } \\
\text { presentations } \\
(\%)\end{array}$ & $\begin{array}{l}\text { Proportion of all } \\
\text { emergency department } \\
\text { presentations resulting in } \\
\text { hospital admission (\%) }\end{array}$ \\
\hline 1 & Cycling & 13745 & 26.2 & 18.9 \\
2 & Australian football & 5948 & 11.3 & 9.3 \\
3 & Roller skating/blading & 3403 & 6.5 & 17.9 \\
4 & Basketball & 3308 & 6.3 & 6.5 \\
5 & Soccer & 3148 & 6.0 & 9.8 \\
6 & Trampolining & 3129 & 6.0 & 18.5 \\
7 & Skateboarding & 2697 & 5.1 & 17.4 \\
8 & Cricket & 1945 & 3.7 & 8.2 \\
9 & Netball & 1924 & 3.7 & 3.3 \\
10 & Rugby & 1910 & 3.6 & 13.1 \\
\hline
\end{tabular}

departments to be a valuable source of sports injury data. ${ }^{11-20}$ For example, Tenverger ${ }^{14}$ described all injuries caused by sport that were treated in the trauma department of the University Hospital of Groningen in the Netherlands, over the period 1982-1988. Hospital emergency department data collections are also the basis of the National Electronic Injury Surveillance System coordinated by the Consumer Product Safety Commission in the United States. ${ }^{15}$ This is one of the major sources of sports injury data in that country.

Between 1986 and 1995, the National Injury Surveillance Unit (NISU) in Australia maintained a data collection based on injured people presenting to selected hospital emergency departments around Australia. The fundamental role of the database was to identify local injury patterns within areas of each Australian state and territory based on local data collection systems in hospital emergency departments. The aim of this paper is to redress the lack of community based information on sports injury in Australia. This is achieved by capitalising on data collected through the existing national injury surveillance system. The paper therefore describes all sports and active recreation injury cases recorded in the NISU database for the period 1989-1993.

This paper considers activities participated in for both sport and active recreation (including non-organised sport and activities such as horse riding, roller skating/blading, cycling, water ski-ing). Many active recreational activities are similar to their formalised sporting counterparts. Furthermore, the potential for prevention of injuries at the formal levels of play has implications for preventive messages directed at the social or recreational level of play. Because the larger numbers of participants are not involved in organised sport, it is important to consider recreational activities as well.

\section{Methods}

Emergency department presentation data collated by NISU were provided to the authors for the purposes of the research presented in this paper.

The NISU does not provide comprehensive coverage of whole states. Over the period 1989-1993, 74 public hospitals and other medical centres contributed to the NISU data collection through state injury surveillance systems. Furthermore, not all of the hospitals and medical centres contributed data over the full five year period 1989-1993. However, the large number of records accumulated from around Australia over part, or all, of that period can facilitate description of the common categories of injuries and their associated factors. Informal comparisons of the emergency department data with those describing hospital admissions indicate that the former provides a good representation of the broad patterns of injury in Australia (NISU, personal communication).

The injury surveillance in hospital emergency departments was facilitated by a standardised data collection form and data analysis system throughout Australia. The first part of the form was completed by the injured person, or their parent, and included a description of the circumstances associated with the injury event. This included age and sex, time and place of injury, the context of the injury, use of safety equipment, and the activity being undertaken at the time of the injury. The text narrative description of the injury event was based on self reported precursor behaviours, and so some caution may need to be used in fully interpreting this information. The treating doctor had responsibility for completing the second half of the form on which diagnosis and treatment details were recorded.

Sports injuries were identified in the NISU database by the context of the activity being undertaken at the time the injury occurred: sport (organised competition or practice; informal; unspecified) or active recreation (playing or general activity; indoor active recreation or hobby; outdoor active recreation or hobby on land; outdoor active recreation or

Table 2 Body region injured in children during sports and recreation activities

\begin{tabular}{|c|c|c|c|c|c|c|}
\hline \multirow[b]{2}{*}{ Sport } & \multirow[b]{2}{*}{$\begin{array}{l}\text { Total number of } \\
\text { injuries }\end{array}$} & \multicolumn{5}{|c|}{ Distribution of injured body regions (\%) } \\
\hline & & Head & $\begin{array}{l}\text { Upper } \\
\text { extremity }\end{array}$ & $\begin{array}{l}\text { Lower } \\
\text { extremity }\end{array}$ & Trunk & $\begin{array}{l}\text { Unspecified and } \\
\text { other regions }\end{array}$ \\
\hline Cycling & 17585 & 29.6 & 34.7 & 26.6 & 5.0 & 4.3 \\
\hline Australian football & 7075 & 17.3 & 53.4 & 22.8 & 4.7 & 1.9 \\
\hline Roller skating/blading & 3707 & 5.9 & 74.4 & 14.3 & 2.0 & 3.3 \\
\hline Basketball & 3722 & 12.4 & 58.5 & 25.1 & 2.0 & 1.9 \\
\hline Soccer & 3630 & 12.7 & 43.4 & 39.1 & 3.1 & 1.6 \\
\hline Trampolining & 3547 & 19.8 & 42.3 & 25.5 & 4.9 & 7.5 \\
\hline Skateboarding & 3161 & 18.4 & 54.3 & 17.6 & 2.4 & 7.2 \\
\hline Cricket & 2345 & 44.2 & 33.9 & 15.5 & 3.2 & 3.2 \\
\hline Netball & 2165 & 5.8 & 54.4 & 37.3 & 1.4 & 1.1 \\
\hline Rugby & 2312 & 21.3 & 47.1 & 23.2 & 6.5 & 1.9 \\
\hline
\end{tabular}

More than one injury per case was sometimes reported. The percentages correspond to the distribution of injured body regions across all injuries for a given sport. 
Table 3 Nature of sports injury in children

\begin{tabular}{|c|c|c|c|c|c|c|c|c|}
\hline \multirow[b]{2}{*}{ Sport } & \multirow[b]{2}{*}{$\begin{array}{l}\text { Total number } \\
\text { of injuries }\end{array}$} & \multicolumn{7}{|c|}{ Proportion of types of injury (\%) } \\
\hline & & Laceration & $\begin{array}{l}\text { Superficial } \\
\text { abrasion }\end{array}$ & $\begin{array}{l}\text { Haematoma, } \\
\text { bruising }\end{array}$ & $\begin{array}{l}\text { Inflammation, } \\
\text { swelling, pain }\end{array}$ & Fracture & $\begin{array}{l}\text { Sprain or } \\
\text { strain }\end{array}$ & Other \\
\hline Cycling & 17585 & 22.3 & 18.1 & 13.5 & 5.4 & 20.8 & 6.9 & 13 \\
\hline Australian football & 7075 & 5.9 & 1.3 & 18 & 10.7 & 29.1 & 23.6 & 11.4 \\
\hline Roller skating/blading & 3707 & 14.9 & 10.3 & 12.6 & 5.4 & 34.9 & 12.1 & 9.9 \\
\hline Basketball & 3722 & 4.3 & 2.1 & 15.4 & 9.9 & 26.1 & 33.3 & 8.8 \\
\hline Soccer & 3630 & 5 & 1.7 & 18.9 & 10.4 & 29.5 & 26.4 & 8.2 \\
\hline Trampolining & 3547 & 13.1 & 1.4 & 13.6 & 7.9 & 34.7 & 19.8 & 9.5 \\
\hline Skateboarding & 3161 & 13.4 & 3.9 & 5.8 & 1.9 & 53.4 & - & 20.7 \\
\hline Cricket & 2345 & 17.8 & 2.9 & 30.2 & 7.5 & 17.8 & 12.4 & 11.4 \\
\hline Netball & 2165 & 1.2 & 2.6 & 14.9 & 10.7 & 22 & 43.5 & 4.8 \\
\hline Rugby & 2312 & 4.4 & 1.1 & 15.9 & 12.5 & 29.1 & 25 & 11.6 \\
\hline
\end{tabular}

Values are the proportion of all injuries, of a particular type, for each sport.

hobby on water; other leisure). It has been estimated that over $86 \%$ of all cycle use in Australia is for sport, exercise or recreational purposes, rather than for commuting. ${ }^{21}$ For this reason, the data described in this paper contain $86 \%$ of all cycling injuries in children and $89 \%$ of all adult cases.

Particular sports and recreation activities were identified from specific codes and from a narrative text description of the injury. Injury severity was determined by using the proxy measure of admission to hospital after attendance at an emergency department, since only the more severe injuries would require hospital admission. Of course, admission to hospital may also reflect complexity of treatment, which may bear little relation to the actual injury severity.

The sports and active recreation activities were ranked in terms of the number of injury presentations or the proportion of presentations resulting in hospital admission. On the basis of these measures, a crude ranking of the sports leading to the greatest number of injury presentations and hospital admissions can be obtained. It is important to recognise, however, that just because a particular sport ranks highly in terms of the number of presentations related to it, this does not necessarily mean that this particular activity has the highest incidence of injury. It may just reflect a large number of participants in that sport.

The sampling frame of the NISU data collection purposely oversampled paediatric hospitals. For this reason, children were defined as being aged less than 15 years and adults as all people aged at least 15 years. It is not possible to compare data for adults and children except as proportions of the child and adult subsets because of the sampling fractions.

Table 4 The 10 most common sport and active recreation activities leading to an adult emergency department injury presentation in Australia, 1989-93

\begin{tabular}{|c|c|c|c|c|}
\hline $\begin{array}{l}\text { Rank } \\
\text { order }\end{array}$ & Sport & $\begin{array}{l}\text { No of } \\
\text { presentations }\end{array}$ & $\begin{array}{l}\text { Proportion of all } \\
\text { sports injury } \\
\text { presentations (\%) }\end{array}$ & $\begin{array}{l}\text { Proportion of all emergency } \\
\text { department presentations } \\
\text { resulting in hospital } \\
\text { admission (\%) }\end{array}$ \\
\hline 1 & Australian football & 10122 & 21.6 & 7.5 \\
\hline 2 & Cycling & 4672 & 10.0 & 14.4 \\
\hline 3 & Soccer & 3777 & 8.1 & 7.1 \\
\hline 4 & Rugby & 3636 & 7.8 & 10.9 \\
\hline 5 & Cricket & 3408 & 7.3 & 5.4 \\
\hline 6 & Basketball & 3228 & 6.9 & 4.1 \\
\hline 7 & Netball & 3098 & 6.6 & 2.5 \\
\hline 8 & Hockey & 1219 & 2.6 & 3.2 \\
\hline 9 & Martial arts & 882 & 1.9 & 5.6 \\
\hline 10 & Dancing & 869 & 1.9 & 5.2 \\
\hline
\end{tabular}

Data are therefore presented for children and adults separately.

Because of the nature of the NISU data, all data in this paper are given as frequencies (\%) or the number of reported injury cases.

\section{Results}

Over the period 1989-1993, 51203 children and 46837 adults were reported as attending an NISU emergency department for the treatment of an injury sustained during sport or active recreation. This corresponds to $20 \%$ of all child and $18 \%$ of all adult injury presentations to these emergency departments over this period. Just over $14 \%$ of the children injured during sport and active recreation activities were subsequently admitted to hospital for further treatment, compared with $8 \%$ of the injured adults.

\section{EMERGENCY DEPARTMENT PRESENTATIONS BY} CHILDREN FOR SPORTS AND ACTIVE RECREATION INJURIES

Table 1 lists the 10 most frequent sporting and active recreation activities that led to a child presenting with an injury at one of the NISU participating hospitals. Together, these 10 activities accounted for 41157 injury cases or about $78 \%$ of all sport and active recreation emergency department injury presentations in children. The remainder of this discussion of child injuries will focus on these 10 sports.

The organised sport most frequently associated with a child sports or active recreation injury presentation at an emergency department was Australian football, which accounted for $11.3 \%$ of all such injury presentations. The other popular sports of basketball, soccer, cricket, netball, and rugby also appeared in the top 10 ranking. The ranking of roller skating/ blading, skateboarding, and cycling in the top 10 activities highlights the potential for "wheeled" active recreation activities to lead to injury because of the speed and the surfaces on which the participants fall.

Of the sports and active recreation activities shown in table 1, cycling and trampolining tended to produce the most severe injuries, with almost one fifth requiring hospital admission. The proportion of emergency department presentations resulting in hospital admission was higher for the wheeled active recreation activities and trampolining than for any of the organised sports. Rugby was also associated 
Table 5 Body region injured in adults

\begin{tabular}{|c|c|c|c|c|c|c|}
\hline \multirow[b]{2}{*}{ Sport } & \multirow[b]{2}{*}{$\begin{array}{l}\text { Total number of } \\
\text { injuries }\end{array}$} & \multicolumn{5}{|c|}{ Distribution of injured body regions (\%) } \\
\hline & & Head & Upper extremity & $\begin{array}{l}\text { Lower } \\
\text { extremity }\end{array}$ & Trunk & $\begin{array}{l}\text { Unspecified and } \\
\text { other }\end{array}$ \\
\hline Australian football & 12710 & 20.4 & 37.7 & 32.6 & 7.2 & 2.0 \\
\hline Cycling & 6859 & 21.6 & 43.7 & 25.2 & 6.8 & 4.7 \\
\hline Soccer & 4626 & 11.6 & 21.5 & 58.9 & 4.9 & 3.3 \\
\hline Rugby & 4921 & 26.6 & 36.4 & 26.6 & 8.2 & 1.9 \\
\hline Cricket & 3846 & 16.6 & 32.6 & 22.8 & 4.2 & 3.1 \\
\hline Basketball & 3831 & 10.7 & 34.8 & 48.7 & 2.8 & 2.9 \\
\hline Netball & 3587 & 4.9 & 27.5 & 63.9 & 2.0 & 1.8 \\
\hline Hockey & 1436 & 30.6 & 33.1 & 29.7 & 4.1 & 2.5 \\
\hline Martial arts & 1096 & 14.1 & 35.9 & 39.1 & 8.7 & 2.1 \\
\hline Dancing & 991 & 9.5 & 21.8 & 63.3 & 3.3 & 2.1 \\
\hline
\end{tabular}

The number of cases refers to the total number of injuries. The percentages correspond to the distribution of injured body regions for a given activity.

with a significant proportion of cases that required hospitalisation for further treatment.

As expected, injuries related to the traditional sports of Australian football, basketball, soccer, cricket, netball, and rugby occurred most frequently in an area designated for organised sports such as an arena or oval. Cycling, skateboarding, and roller skating/ blading injuries were commonly sustained in areas used for transport, including driveways and footpaths. They were also common in residential settings.

Table 2 gives the body regions injured during participation in the 10 most commonly presented sport and active recreation activities for children. Some injured children sustained more than one injury. The total number shown in table 2 therefore corresponds to the total number of injuries, and the remainder of the table shows the distribution of body regions injured, across all injuries for each sport.

The most commonly injured body regions were generally the upper extremities, the lower extremities, and the head/face. Head and facial injuries were most common in cricketers, and were generally associated with hits from the bat or ball. Concussion was more common in cyclists. Upper extremity injuries, particularly wrist injuries, were most common in roller skaters/bladers, but more than half of all individuals with an injury from Australian football, basketball, skateboarding, and netball also had an injury in this region of the body. Soccer and netball were associated with more injuries of the lower extremities, on a percentage basis, than any other sport.

Table 3 shows that fractures were the most common type of injury in skateboarding, representing $53.4 \%$ of all injuries. They were also common in roller skating/blading (34.9\%), trampolining $(34.7 \%)$, soccer $(29.5 \%)$, Australian football $(29.1 \%)$, and rugby $(29.1 \%)$. Sprains and strains were most common in netball and basketball, whereas a large proportion of cricketers suffered bruising. Many of the cycling related injuries were lacerations. Fractures were the most common type of injury leading to subsequent admission to hospital for further treatment.

EMERGENCY DEPARTMENT SPORTS INJURY PRESENTATIONS BY ADULTS

Table 4 lists the top 10 most frequent sporting and active recreation activities that led an adult to present at one of the NISU participating hospitals. Together, these 10 activities accounted for 34911 injury cases or $74 \%$ of all sport and active recreation injuries presenting in this age group.

Together, the three football codes accounted for $37.5 \%$ of all sports injuries in adults. All of the football codes were ranked higher than the other sports, except for cycling which was more common than soccer and rugby but not as common as Australian football. As was the case with children, the organised sport most often associated with an adult sports injury presentation at an emergency department was Australian football, which accounted for $21.6 \%$ of all sports and active recreation injury presentations. Injuries sustained during cycling, soccer, rugby, cricket, basketball, and netball also accounted for a large proportion of injury cases. This is in contrast with the situation in children where the 10 most frequent reasons for presenting to an emergency department included a large number of active recreation activities.

More of the people with a cycling injury were likely to be admitted to hospital for further treatment than those with injuries sustained during any other sport or active recreation activity listed in table 4 . Over $10 \%$ of the rugby injuries were severe enough to require hospitalisation.

Compared with children, a larger proportion of sports injuries in adults occur during organised competition or practice. Injuries related to the traditional sports occurred most frequently in an area designed for organised sports such as an arena or oval. Areas used for transport, including driveways and footpaths, were the scene of most of the cycling injuries.

Table 5 shows the body regions injured in adults during participation in the 10 most commonly presented sport and active recreation activities. Some injured adults had more than one injury and this table summarises the body regions on an injury basis, rather than an incident basis. The most commonly injured body regions were the upper and lower extremities. As a proportion of all injuries, those to the upper extremities were most common in cyclists but were prevalent in participants in Australian football, rugby, cricket, and hockey. A greater proportion of injuries in netball was associated with the lower extremity than was the case in any other sport. 
Table 6 Nature of injury in adults

\begin{tabular}{|c|c|c|c|c|c|c|c|c|}
\hline \multirow[b]{2}{*}{ Sport } & \multirow[b]{2}{*}{$\begin{array}{l}\text { Total number } \\
\text { of injuries }\end{array}$} & \multicolumn{7}{|c|}{ Proportion of types of injury (\%) } \\
\hline & & Laceration & $\begin{array}{l}\text { Superficial } \\
\text { abrasion }\end{array}$ & $\begin{array}{l}\text { Haematoma, } \\
\text { bruising }\end{array}$ & $\begin{array}{l}\text { Inflammation, } \\
\text { swelling, pain }\end{array}$ & Fracture & $\begin{array}{l}\text { Sprain or } \\
\text { strain }\end{array}$ & Other \\
\hline Australian football & 12710 & 8.9 & 1.1 & 14.2 & 10.7 & 22.7 & 29.8 & 12.6 \\
\hline Cycling & 1096 & 18.1 & 47.5 & 12.4 & 6.7 & 19.2 & 8.2 & 10.5 \\
\hline Soccer & 4626 & 7.1 & 1.1 & 15.2 & 11.2 & 20.8 & 37.1 & 7.3 \\
\hline Rugby & 4921 & 11.1 & 1.2 & 13.5 & 10.1 & 21.8 & 29.0 & 13.1 \\
\hline Cricket & 3846 & 11.8 & 1.2 & 19.6 & 10.6 & 20.7 & 26.0 & 11.5 \\
\hline Basketball & 3831 & 6.4 & 0.8 & 11.1 & 8.8 & 18.3 & 45.7 & 8.7 \\
\hline Netball & 3587 & 2.0 & 1.4 & 9.3 & 10.0 & 13.3 & 57.5 & 6.3 \\
\hline Hockey & 1436 & 23.7 & 1.9 & 23.0 & 11.3 & 15.3 & 17.7 & 7.3 \\
\hline Martial arts & 1096 & 7.2 & 0.9 & 18.9 & 12.2 & 25.1 & 26.4 & 9.2 \\
\hline Dancing & 991 & 9.8 & 0.9 & 11.4 & 10.6 & 17.8 & 40.1 & 8.9 \\
\hline
\end{tabular}

Table 6 shows that sprains and strains were the most common type of injury in adults participating in Australian football, soccer, rugby, cricket, basketball, netball, the martial arts, and dancing. This suggests that hospital emergency departments are a preferred place for the treatment of strains and sprains by some sports participants, despite the wide availability of other treatment centres such as sports medicine and physiotherapy clinics.

\section{Discussion}

The results of this study confirm the large contribution that the sports of football (all codes), basketball, netball, hockey, and cricket make to sports injuries in Australia. This is consistent with the findings of Egger. ${ }^{9}$

Football injuries are also predominant in other population based studies of sports injuries, although the particular code contributing the most injuries varies from country to country. In New Zealand, for example, injuries associated with all codes of football accounted for $32.4 \%$ of all attendances at accident and emergency departments for sports injury. ${ }^{22}$ Of these, rugby union contributed $22.4 \%$ of all injuries. In Sweden, on the other hand, soccer was found to account for $42 \%$ of all sports related visits to an emergency room in a total population municipality. ${ }^{16}$ The high contribution of football injuries, of any code, to emergency department sports injury statistics probably reflects the popularity of these sports in these countries and the contact nature of the sport.

Other team sports are also frequently associated with sports injuries presented to emergency departments. For example, basketball and associated sports such as volleyball are consistently ranked highly in emergency department data collections in many countries. ${ }^{16192022}$ Unlike the situation in Australia, winter sports such as ice hockey and skiing are also associated with a relatively large proportion of injuries in countries where ice and snow are major features of the winter seasons. ${ }^{16} 192022$

Despite the rise in specialist clinical services for sport related injury, many patients attend hospital emergency departments. Grimble et $a l^{23}$ found that $7 \%$ of weekend attendances at their accident and emergency department were injured sports participants. Most of the patients that were followed up felt that the accident and emergency department was the most appropriate place for treatment of their sports injury.

Sports injuries treated at a sports injury clinic were compared with those that were treated at a neighbouring accident and emergency department in the United Kingdom. ${ }^{24}$ There were significant differences in the age, sport, injury, and injury site between patients treated at the different health settings. The study also confirmed that both types of treatment setting are important. Hospitals generally treat acute sports injuries whereas sports specialist clinics generally treat chronic injuries.

A study of 1000 consecutive sports injury cases seen at the accident and emergency department of Western Infirmary Hospital, Glasgow found that injured people preferred to present directly to hospital rather than attend their own general practitioner for treatment of a sport injury. ${ }^{12}$ A survey of sport and recreational injuries presenting to a general practitioner clinic in Melbourne concluded that patients prefer to attend that setting for injury treatment if their injury is not too severe. ${ }^{25}$ This is particularly the case if the practice is close to their home and there is not too long a wait for treatment.

The major advantage of the emergency department data presented here is that they represent the largest and most comprehensive source of sports injury data across a broad range of injuries at the community level in Australia, to date. Hahn et $a l^{26}$ in their study of sport and active recreational fishing injuries in Australia, also reported that this routine hospital emergency department injury surveillance system provides the most consistently recorded data available on a national level. Another advantage is that emergency department records contain data on the majority of the most serious injuries.

The NISU data presented in this paper do have important limitations, however. The collected data are not suitable for demonstrating the absolute size or scope of the sports injury problem in the Australian community. Because it contains injured cases from only a sample of hospitals in each catchment area, its main value is in providing descriptive information on the nature, causes, and severity of injuries. Furthermore, not all sports injuries are treated at such departments. Unfortunately, it is not possible to quantify the magnitude of this under-reporting, because full data 
are not currently available from the other potential treatment sources (sports medicine clinics, general practice clinics).

Future sports injury surveillance systems should include statewide or representative samples of emergency departments. It is important that these are supplemented with data on sports injury cases that present to other treatment sources such as sports medicine clinics, general practitioners, and physiotherapists. It is only when these data are available that the full extent of the sports injury problem in Australia will be able to be determined.

In conclusion, the NISU data provide quite detailed information about the nature and causes of sports and active recreation injuries by individual activities so that the events and behaviours preceding the injuries can be identified. Emergency departments are a rich source of sports and active recreation injury data in Australia for both acute injuries and those caused by strains or overuse. The inclusion of injury data for active recreation activities is a particular strength of emergency department collections, since few other sources of these data are available.

The database is limited in that it is not suitable for demonstrating the absolute size or scope of the sports injury problem in the Australian community because it does not provide complete coverage of whole states and only a proportion of injured sports participants present at hospital emergency departments for treatment.

Participation data are needed to translate these injury statistics into injury rates so that the relative risk of injury in various sports can be compared. However, the limited information available about sports injuries from NISU data collected in emergency departments in Australia indicates that sports are a common context for injury at the community level. The detailed data presented indicate issues that warrant further study and intervention.

This research was undertaken by the authors while they were all working at the Monash University Accident Research Centre (MUARC). Some revisions were made to the manuscript while C F was employed at Deakin University. The study was funded $\mathrm{C} F$ was employed at Deakin University. The study was funded
by the National Sports Research Centre (Australian Sports by the National Sports Research Centre (Australian Sports C F was supported by a Public Health Research and DevelopC F was supported by a Public Health Research and Development Committee Research Fellowship while employed at providing the Australia-wide data from emergency department presentations. Some of the material in this paper was presented at the 1994 International Conference of Science and Medicine in Sport, Brisbane.

1 Finch C, Ozanne-Smith J, Williams F. The feasibility of mproved data collection methodologies for sports injuries. Monash University Accident Research Centre. 1996:69.

2 Dixon M, Fricker P. Injuries to elite gymnasts over 10 years. Med Sci Sport Exerc 1993;25:1322-9.

3 Seward $\mathrm{H}$, Orchard J, Hazard $\mathrm{H}$, et al. Football injuries in Australia at the elite level. Med f Aust 1993;105:113-20.

4 Purdam C. A survey of netball and basketball injuries. Excel 1987;3:9-11.

5 Crawford SE, Fricker PA. Injuries and illness amongst young elite female basketballers at the Australian Institute of Sport 1982-1989. Excel 1990;6:6-12.

6 Fricker P, Maguire K. The prevalence of leg injuries in elite tennis players. Excel 1986;3:2-4.

7 McKay GD, Payne WR, Goldie PA, et al. A comparison of the injuries sustained by female basketball and netball the injuries sustained by female basketball
players. Aust $₹$ Sci Med Sport $1996 ; 28: 12-18$.

players. Aust f Sci Med Sport 1996;28:12-18.
8 Bennell K, Crossley K. Musculoskeletal injuries in track and field: incidence, distribution and risk factors. Aust $\mathcal{f}$ Sci field: incidence, distribution

9 Egger G. Sports injury in Australia: causes, costs and prevention. Health Promotion fournal of Australia 1991;1: 28-33.

10 Watt GM, Ozanne-Smith J. Non-fatal injuries to young Victorians, 1986-1991. Med F Aust 1994;160:790-4.

11 Nolan T, Penny M. Epidemiology of non-intentional injuries in an Australian urban region: results from injury surveillance. F Paediatr Child Health 1992;28:27-35.

12 Pickard MA, Tullett WM, Patel AR. Sports injuries as seen at an accident and emergency department. Scott Med $\mathcal{F}$ 1988;33:296-7.

13 Nicholl JP, Coleman P, Williams BT. The epidemiology of sports and exercise related injury in the United Kingdom. Br f Sports Med 1995;29:232-8.

14 Tenvergert E. Trends in sports injuries, 1982-1988: an in-depth study on four types of sport. $\mathcal{f}$ Sports Med Phys Fitness 1992;32:214-20.

15 National Electronic Injury Surveillance System (NEISS) Reports. Washington DC: National Consumer Product Safety Commission

16 de Loes $M$. Medical treatment and costs of sports-related njuries in total population. Int $\mathcal{F}$ Sports Med 1990;11:6672 .

17 Kyle SB, Adler P, Monticone RC. Reducing youth baseball injuries with protective equipment. Consumer Product Safety Review 1996;1:1-4.

18 Lyons RA, Vui Lo S, Heaven M, et al. Injury surveillance in children: usefulness of centralised database of accident and emergency attendances. Injury Prevention 1995;1:173-6.

19 Ellison LF, Mackenzie SG. Sports injuries in the database of the Canadian Hospitals Injury Reporting and Prevention program: an overview. Chronic Disease in Canada 1993;14: program:

20 Spencer Jones R, Taggart T. Sport related injuries attending the accident and emergency department. Br $\mathcal{F}$ Sports Med 1994;28:110-11.

21 Spectrum Research. Survey of cyclists characteristics and cycling patterns. Report prepared for the Victorian State Bicycle Committee. October 1986.

22 Hume PA, Marshall SW. Sports injuries in New Zealand: exploratory analyses. New Zealand fournal of Sports Medicine 1994;22:18-22.

23 Grimble S, Kendall IG, Allen MJ. An audit of care received by patients injured during sporting activities. Archives of Emergency Medicine 1993;10:203-8.

24 Rowell S, Rees-Jones A. Injuries treated at a sports injury clinic compared with a neighbouring accident and clinic compared with a neighbouring accident and
emergency department. Br f Sports Med 1988;22:157-60.

25 Jago D, Finch C. A survey of sporting and recreational injuries presenting to a general practice. Aust Fam Physician 1998 (in press).

26 Hahn S, Reilly C, Farr T, et al. A study of factors contributing to injury and mortality of Australian sport and active recreational anglers. Aust f Sci Med Sport 1993;25:89-94. 